
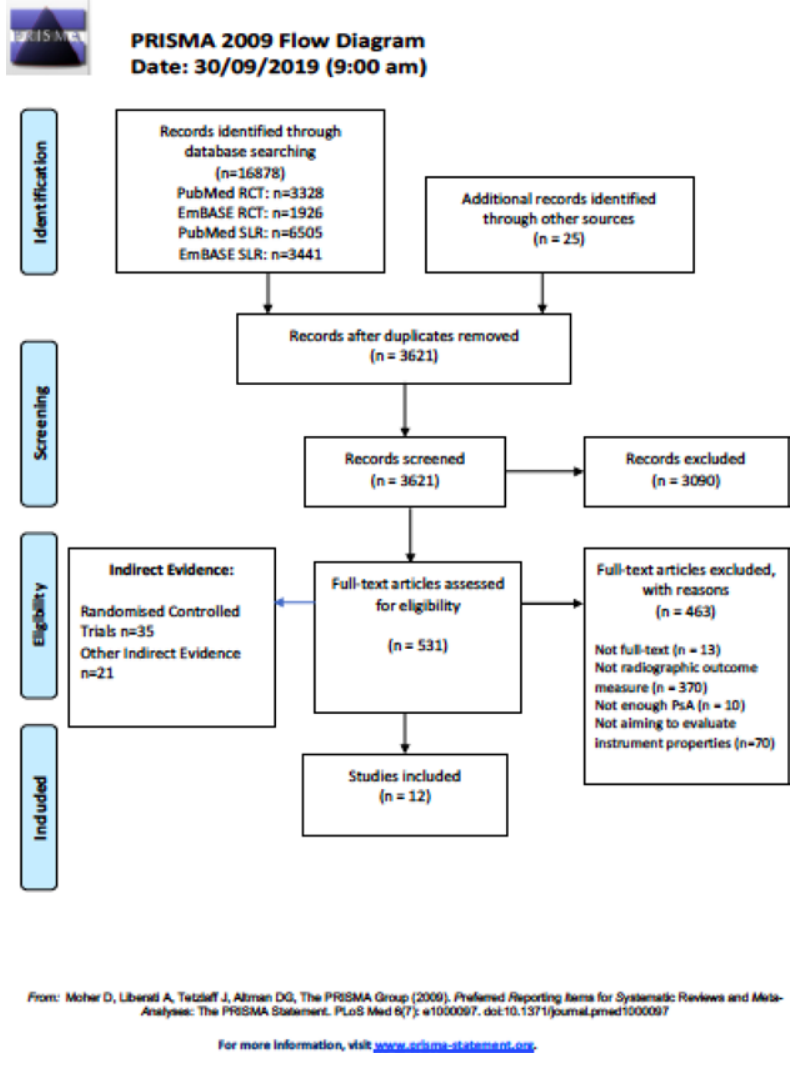

Figure 2. PRISMA Diagram
Gilead, Janssen, Novartis, Pfizer, UCB, Speakers bureau: Received speaker fees from Abbvie, Janssen, Novartis, Pfizer, UCB., Heidi Bertheussen: None declared, Lori Schick: None declared, Niti Goel Shareholder of: UCB and Galapagos, Consultant of: VielaBio, Mallinckrodt, and IMMVention, Alexis Ogdie Grant/research support from: Pfizer, Novartis, Consultant of: Abbvie, Amgen, BMS, Celgene, Corrona, Janssen, Lilly, Pfizer, Novartis, Ana-Maria Orbai Grant/research support from: Abbvie, Eli Lilly and Company, Celgene, Novartis, Janssen, Horizon, Consultant of: Eli Lilly; Janssen; Novartis; Pfizer; UCB. Ana-Maria Orbai was a private consultant or advisor for Sun Pharmaceutical Industries, Inc, not in her capacity as a Johns Hopkins faculty member and was not compensated for this service., Pil Hoejgaard: None declared, Laura C Coates: None declared, Vibeke Strand Consultant of: AbbVie, Amgen, Biogen, Celltrion, Consortium of Rheumatology Researchers of North America, Crescendo Bioscience, Eli Lilly, Genentech/Roche, GlaxoSmithKline, Hospira, Janssen, Merck, Novartis, Pfizer, Regeneron Pharmaceuticals, Inc., Sanofi, UCB, Dafna D Gladman Grant/research support from: AbbVie, Amgen Inc., BMS, Celgene Corporation, Janssen, Novartis, Pfizer, UCB - grant/research support, Consultant of: AbbVie, Amgen Inc., BMS, Celgene Corporation, Janssen, Novartis, Pfizer, UCB - consultant, Robin Christensen: None declared, Ying Ying Leung Speakers bureau: Novartis, Janssen, Eli Lilly, Philip J Mease Grant/research support from: Abbott, Amgen, Biogen Idec, BMS, Celgene Corporation, Eli Lilly, Novartis, Pfizer, Sun Pharmaceutical, UCB grant/research support, Consultant of: Abbott, Amgen, Biogen Idec, BMS, Celgene Corporation, Eli Lilly, Novartis, Pfizer, Sun Pharmaceutical, UCB - consultant, Speak ers bureau: Abbott, Amgen, Biogen Idec, BMS, Eli Lilly, Genentech, Janssen, Pfizer, UCB - speakers bureau, William Tillett Grant/research support from: AbbVie, Celgene, Eli Lilly, Janssen, Novartis, Pfizer Inc, UCB, Consultant of: AbbVie, Amgen, Celgene, Lilly, Janssen, Novartis, MSD, Pfizer Inc, UCB, Speakers bureau: AbbVie, Amgen, Celgene, Lilly, Janssen, Novartis, Pfizer Inc, UCB DOI: 10.1136/annrheumdis-2020-eular.2431

\section{AB0738 SAPHO OR PSORIATIC ARTHRITIS?: EVALUATION OF CASPAR CRITERIA IN A COHORT WITH SAPHO.}

M. Aparicio Rovira ${ }^{1}$, M. Aparicio Espinar ${ }^{1}$, L. Gifre ${ }^{1}$, S. Holgado ${ }^{1}$, M. MartínezMorillo $^{1}$, A. Riveros ${ }^{1}$, C. Sanguesa ${ }^{1}$, Á. Prior-Español ${ }^{1}$, A. Nack ${ }^{1}$, I. CasafontSolé ${ }^{1}$, A. Olive' ${ }^{1}$, L. Mateo'. ${ }^{1}$ Hospital Germans Trias i Pujol, Rheumatology Section, Badalona, Spain

Table 1. Summary of Measurement Properties

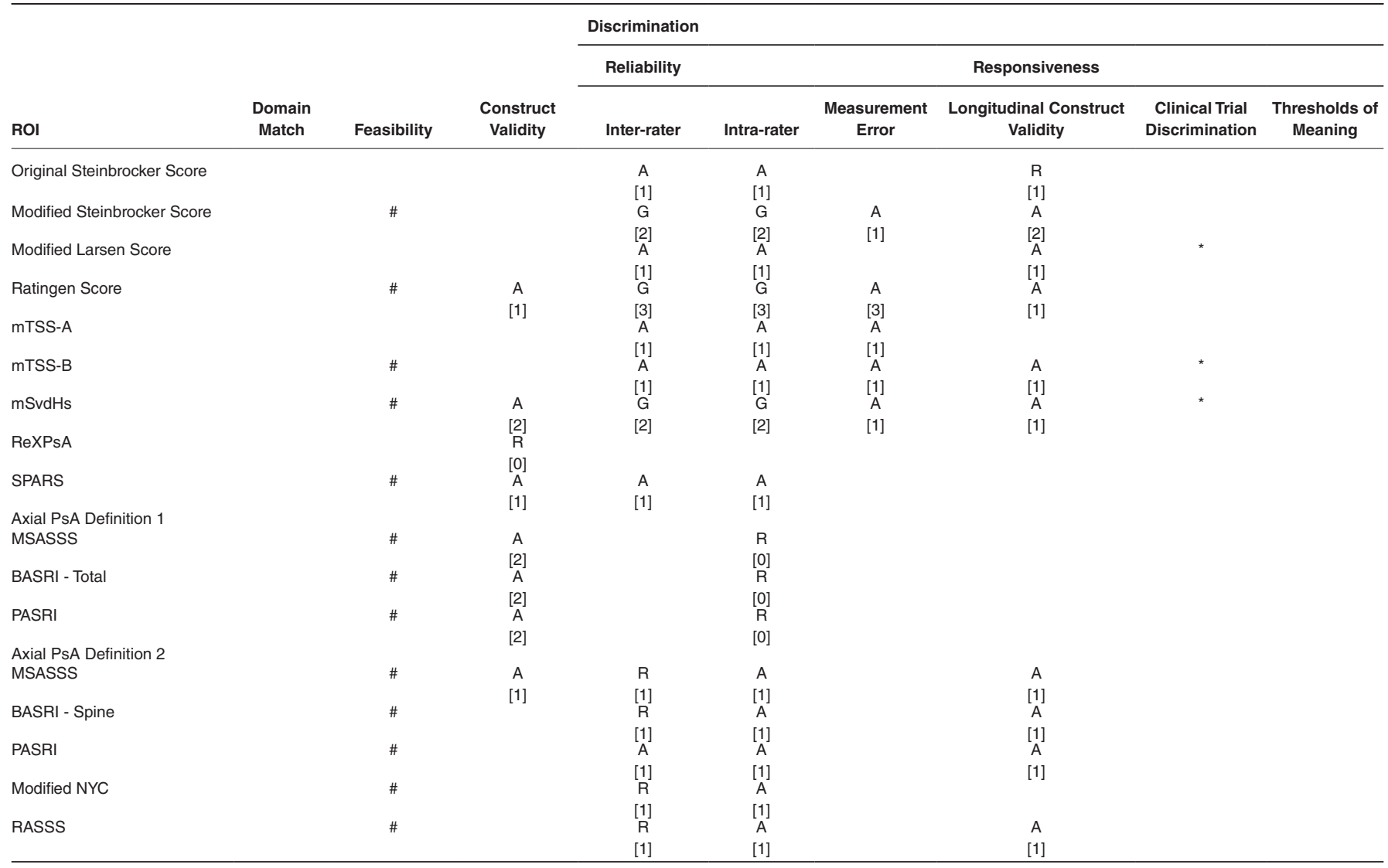

$\mathrm{A}=$ Amber, $\mathrm{R}=$ Red, $\mathrm{G}=$ Green

[Total available studies for synthesis following excluding studies with poor methodology]

${ }^{\star}$ RCT data available but no published effect sizes

\# Feasibility data available 
Background: SAPHO syndrome (synovitis, acne, pustulosis, hyperostosis and osteitis) is an acronym created with the aim of encompassing within the same entity the findings present in a heterogeneous group of patients with various osteoarticular and cutaneous disorders. For years it has been debated whether it is an entity itself or if, on the contrary, it is a specific phenotype of psoriatic arthritis.

Objectives: Determine the relationship between SAPHO syndrome and psoriatic arthritis by comparing the classic criteria of SAPHO with CASPAR in patients previously diagnosed with SAPHO.

Methods: A retrospective study where patients with a diagnosis of SAPHO in the same center (1984-2018) were reviewed. Of a total of 95 patients that met the criteria of Benhamou et al., 46 were excluded due to lack of information to complete the minimum necessary data, so 39 patients were finally included in the study. Demographic data were registered, age at diagnosis, CASPAR criteria (active psoriasis, history of own or familial psoriasis, nail psoriasis, negative RF, dactylitis and new formation/juxta-articular bone proliferation), classical criteria of SAPHO and HLAB27. For the statistical analysis, a Chi-square is applied to determine the differences between the groups with / without CASPAR criteria.

Results: Of the sample of 39 subjects diagnosed with SAPHO, 15 patients $(38 \%)$ met CASPAR criteria $(4 \mathrm{M} / 11 \mathrm{~W})$, with a median age at diagnosis of 42 years (range $21-50)$. Of them, $8(60 \%)$ had active cutaneous psoriasis, $10(73 \%)$ had a family or personal history of psoriasis, 6 (40\%) had psoriatic nail dystrophy, $14(93 \%)$ had negative FR, $3(20 \%)$ had presented some episode of dactylitis and $10(73 \%)$ had juxta-articular new bone formation. Of the 15 patients who met CASPAR criteria, $9(67 \%)$ had synovitis, $2(13 \%)$ acne, $4(26 \%)$ pustulosis, $13(87 \%)$ hyperostosis and $12(80 \%)$ osteitis. HLAB27 was positive in 1 patient $(2.5 \%)$ of the group that met CASPAR criteria. Of the patients who did not fulfill CASPAR criteria $(9 \mathrm{M} / 15 \mathrm{~W})$, the median age at diagnosis was 44.5 years (range 10-70). None of them had active cutaneous psoriasis, psoriatic nail distrophy or dactylitis, $1(4 \%)$ had a family or personal history of psoriasis, all had RFand $3(12.5 \%)$ had juxta-articular bone new formation (Table 1). Synovitis was observed more frequently in patients who met CASPAR criteria than in those who did not $(67 \%$ vs $25 \%$, p 0.01$)$. In contrast, osteitis was present more frequently in patients who did not meet CASPAR criteria ( $80 \%$ vs $96 \%$ p 0.05$)$ and pustulosis, although it was not statistically significant ( $50 \%$ vs $26 \%$, p 0.07). Among patients who did not meet CASPAR criteria only 1 met the 5 classic SAPHO criteria and another 3 met 4 .

Table 1.

\begin{tabular}{|c|c|c|c|}
\hline & & & \\
\hline & CASPAR + (15) & CASPAR - (24) & \\
\hline \multicolumn{3}{|l|}{ CASPAR CRITERIA } & \\
\hline Current psoriasis & $60 \%(8)$ & $0 \%(0)$ & \\
\hline History of psoriasis & $73 \%(10)$ & $4 \%(1)$ & \\
\hline Psoriatic nail dystrophy & $40 \%(6)$ & $0 \%(0)$ & \\
\hline FR - & $93 \%(14)$ & $100 \%(24)$ & \\
\hline Dactylitis & $20 \%(3)$ & $0 \%(0)$ & \\
\hline Juxta-articular new bone formation & $73 \%(10)$ & $12.5 \%(3)$ & \\
\hline \multicolumn{4}{|l|}{ SAPHO CRITERIA } \\
\hline Synovitis & $67 \%(9)$ & $25 \%(6)$ & $\mathrm{p} 0.01$ \\
\hline Acne & $13 \%(2)$ & $30 \%(7)$ & p 0.1 \\
\hline Pustulosis & $26 \%(4)$ & $50 \%(12)$ & p 0.01 \\
\hline Hyperostosis & $87 \%(13)$ & $92 \%(22)$ & p 0.3 \\
\hline Osteitis & $80 \%(12)$ & $96 \%(23)$ & p 0.05 \\
\hline HLAB27+ & $1(2.5 \%)$ & $0(0 \%)$ & \\
\hline
\end{tabular}

Conclusion: Approximately one third (38\%) of patients diagnosed with SAPHO meet criteria for psoriatic arthritis, the most notable variables being active psoriasis or a history of psoriasis. Synovitis manifests more frequently in patients with CASPAR criteria and osteitis more present in patients who did not meet them.

Acknowledgments: Rheumatology Service of the Germans Trias i Pujol Hospital Disclosure of Interests: None declared

DOI: 10.1136/annrheumdis-2020-eular.6014

\section{AB0739 1 PSORIATIC ARTHRITIS RELATED-UVEITIS, OUR EXPERIENCE IN A THIRD-LEVEL SPANISH CENTRE.}

J. Arroyo Palomo $^{1}$, L. Villalobos-Sánchez ${ }^{1}$, V. García García ${ }^{1}$, V. Aguado Casanova $^{1}$, L. Calvo Sanz ${ }^{1}$, I. Del Bosque Granero ${ }^{1}$, F. J. Huelin Alcubierre ${ }^{1}$, J. J. Gonzalez Lopez ${ }^{1}$, M. Revenga Martínez ${ }^{1}{ }^{1}$ Hospital Ramón y Cajal, Madrid, Spain

Background: The occurrence of uveitis in patients with psoriatic arthritis (PsA) has been documented as the most frequent and important extra-articular manifestation, with an estimated frequency of 7 and $18 \%$. Clinical onset may be acute or insidious, and it may be accompanied by other ocular manifestations.
In contrast with spondyloarthropathy related-uveitis, PsA associated tends to be insidious, bilateral, chronic or posterior.

Objectives: To describe clinic and immunological features of psoriatic arthritis patients in our centre, especially those with associated-uveitis and to define its frequency.

Methods: A retrospective, descriptive and single-centre study (1985-2017) of 494 patients diagnosed with PsA according to the criteria of an expert rheumatologist was conducted. All patients were studied according to a standard protocol. The group was divided into 3 articular categories: pure axial, pure peripheric and mixed. Data regarding enthesitis and dactylitis, as well as HLA-Cw6 and HLA-B27 were extracted, from those available. Ophthalmologic and cutaneous involvement was registered. 216 patients were excluded because of data absence or alternative plausible diagnosis. Descriptive analyses were applied.

Results: Eight patients had uveitis (2,9\% in this series), only one case developed chronic pattern. Acute anterior uveitis was the form of presentation in 6 patients $(75 \%)$. Unilateral involvement was registered in $3(37,5 \%)$, in every case with right eye implication. One patient developed up to 13 episodes of acute anterior uveitis, every episode in the same eye. Median of age at first episode was 54 years, $3(37,5 \%)$ patients were female. Regarding articular categories: $1(12,5 \%)$ pure axial, $3(37,5 \%)$ pure peripheric and $4(50 \%)$ mixed. Enthesitis was regis tered in 2 patients, none of our series developed dactylitis. 3 patients $(37,5 \%)$ were HLA-B27 positive and 2 patients (25\%), HLA-Cw6 positive. 6 cases had cutaneous psoriasis (75\%). Adalimumab was prescribed to 5 PsA related-uveitis patients with optimal control of disease.

Larger PsA cohort without ocular involvement (270 patients), $118(42,4 \%)$ cases were female and median of age was 44 years. Pure axial involvement was present in 20 (7,2\%), pure peripheric, $134(48,2 \%)$ and mixed, $122(43,8 \%) .31$ $(11,15 \%)$ cases developed enthesis involvement and $18(6,5 \%)$, dactylitis. HLAB27 was tested positive in 45 patients $(19,7 \%)$ and HLA-Cw6, in 56 (27,4\%). Cutaneous psoriasis was present in 231 cases $(83,1 \%)$.

Conclusion: Frequency of psoriatic arthritis-uveitis is lower in our sample than referred in bibliography. Further investigations are needed to understand the underlying reasons, although it could be related to the use of biologic treatment and narrower inflammatory activity control in comparison to previous studies. No posterior pole involvement, bilaterality, chronicity nor insidious onset are common in our data; neither axial involvement seems to be predictor for the appearance of uveitis.

References:

[1] Rosenbaum JT. Uveitis in spondyloarthritis including psoriatic arthritis, ankylosing spondylitis, and inflammatory bowel disease. Clin Rheumatol 2015;34:999-1002

[2] Queiro R, et al. Clinical Features and Predictive Factors in Psoriatic Arthritis-Related Uveitis. Semin Arthritis Rheum 2002;31:264-270.

[3] Paiva ES, et al. Characterisation of uveitis in patients with psoriatic arthritis Ann Rheum Dis. 2000;59(1):67-70.

Disclosure of Interests: None declared

DOI: 10.1136/annrheumdis-2020-eular.4835

\section{$\mathrm{AB} 0740$ \\ SECOND-LINE BIOLOGIC DMARDS SURVIVAL IN PSORIATIC ARTHRITIS. DATA FROM A SPANISH THIRD-LEVEL HOSPITAL.}

J. Arroyo Palomo ${ }^{1}$, I. Del Bosque Granero ${ }^{1}$, A. Corral Bote ${ }^{1}$, B. A. Blanco Cáceres ${ }^{1}$, J. Bachiller-Corral ${ }^{1}{ }^{1}$ Hospital Ramón y Cajal, Madrid, Spain

Background: Psoriatic arthritis (PsA) covers a wide spectrum of disease manifestations, including arthritis, enthesitis, dactylitis and axial spondylitis. This range of symptoms presents a challenge to the treating physician. Biologic disease-modifying antirheumatic drugs (bDMARDs) have proven effective through randomized clinical trials; and most international PsA guides include them as main option upon first-line treatment failure. However, studies regarding drug efficacy after bDMARD switching are scarce, lower response rates and drug survival on consecutive lines has been explored in previous research.

Objectives: To assess bDMARDs survival after first-line failure in PsA patients treated in a third-level hospital and to determine baseline clinical and laboratory parameters associated with drug survival.

Methods: We conducted a retrospective, single-centre study. 47 patients who received a second-line bDMARD were included, with diagnosis of PsA according to the criteria of an expert rheumatologist. All patients were studied according to a standard protocol. Data regarding bDMARD prescribed, baseline characteristics, axial or peripheral involvement and immunological profile (included both HLA-B27 and HLA-Cw6) were extracted. C-reactive protein (CRP) and erythrocyte sedimentation rate (ESR) at bDMARD start were included, as well. KaplanMeier, log-rank analyses and Cox regression models were applied.

Results: Of 47 patients receiving a second bDMARD, 55,3\% (26) were female and mean (S.D.) age was 40,6 (12,52) years. Median (interquartile range) disease duration was $10,1(3,7-14,8)$ years. Prescribed drugs were Adalimumab (ADL) $(36,2 \%$, 17), Etanercept (ETN) $(27,6 \%, 13)$, Infliximab (IFX) $(6,4 \%, 3)$, Golimumab (GOL) 